Supporting Information for

\title{
The Influence of Anions on Electron-Transfer Photochromism of Bipyridinium-Derived Metal-Organic Materials
}

Jian-Jun Liu, *† Shu-Biao Xia, † Yao Liu,† Hongbo Suoł Jiaming Liu, § and Xiang Shen†

† Center for Yunnan-Guizhou Plateau Chemical Functional Materials and Pollution Control, Qujing Normal University, Qujing 655011, China.

† School of Pharmacy, Liaocheng University, Liaocheng, Shandong 252059, China.

§School of Metallurgy Engineering, Jiangxi University of Science and Technology, Ganzhou 341000, China

E-mail: jjliu302@163.com 


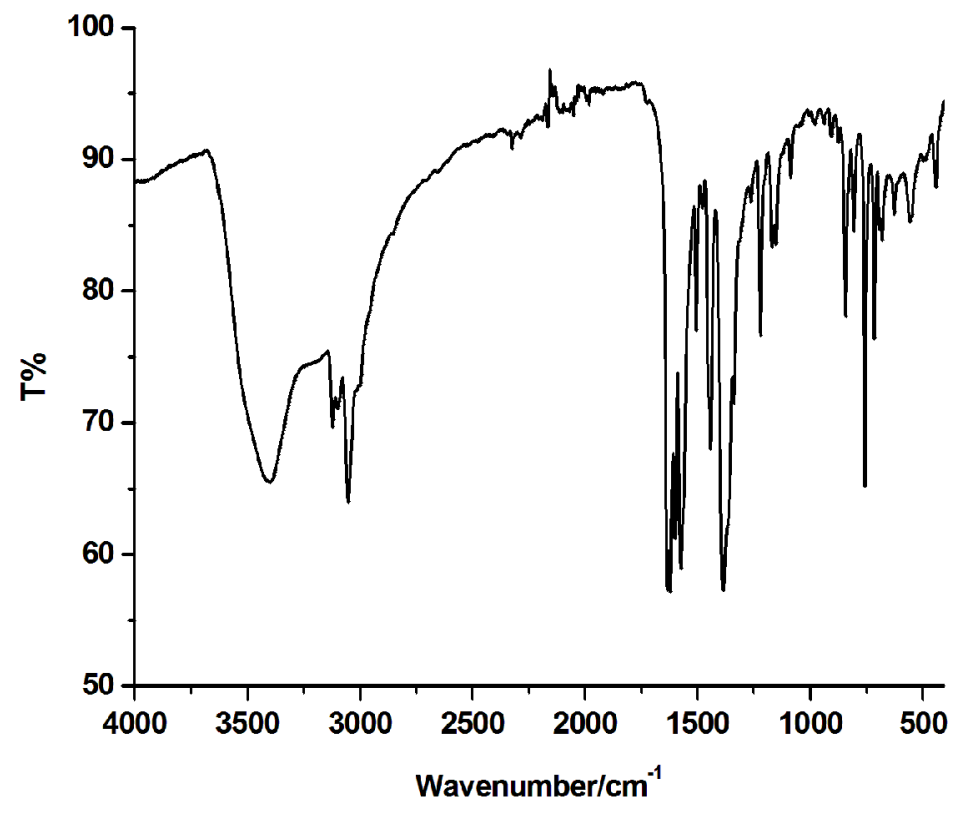

Figure S1. The IR spectrum of complex 1.

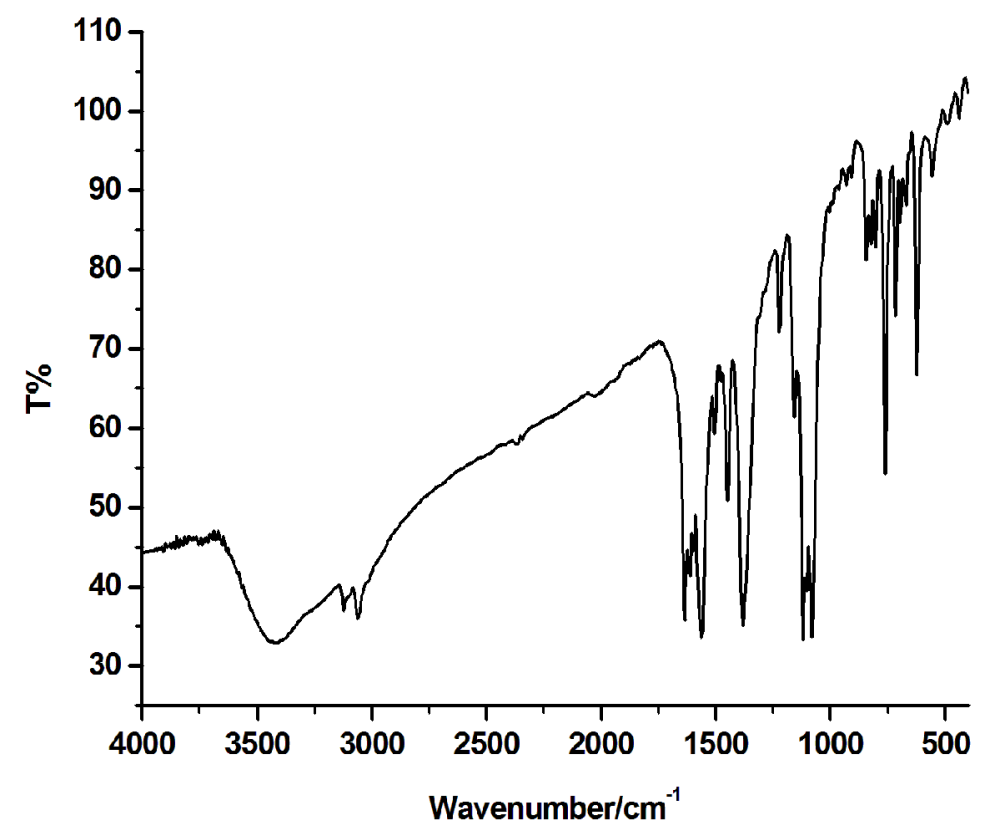

Figure S2. The IR spectrum of complex 2. 


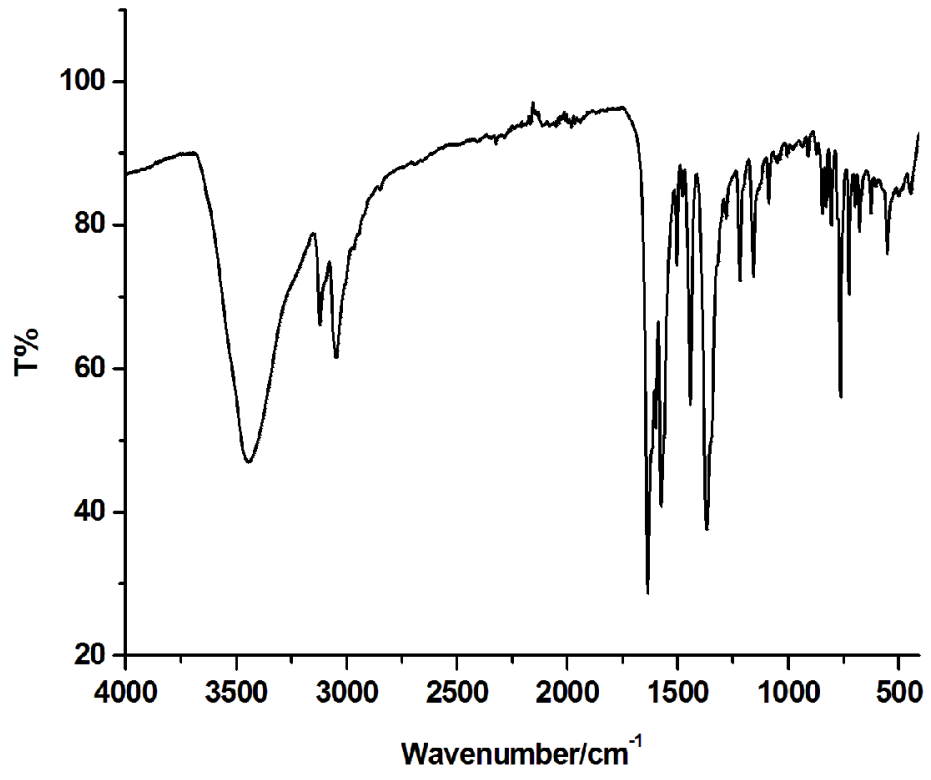

Figure S3. The IR spectrum of complex 3.

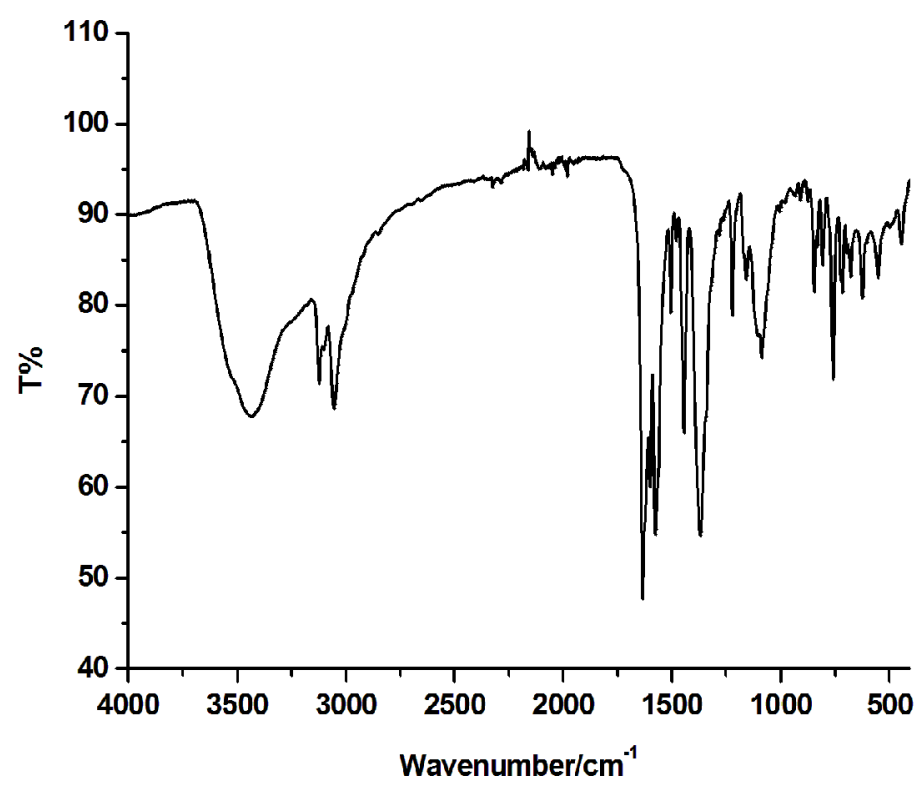

Figure S4. The IR spectrum of complex 4. 


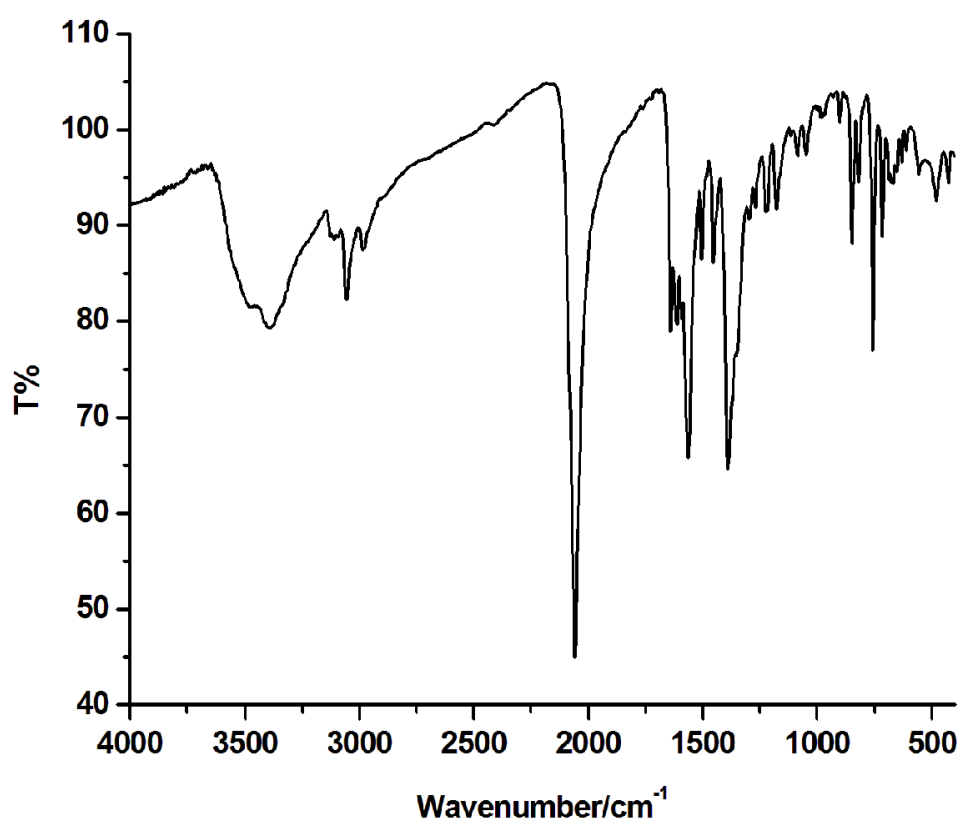

Figure S5. The IR spectrum of complex 5.

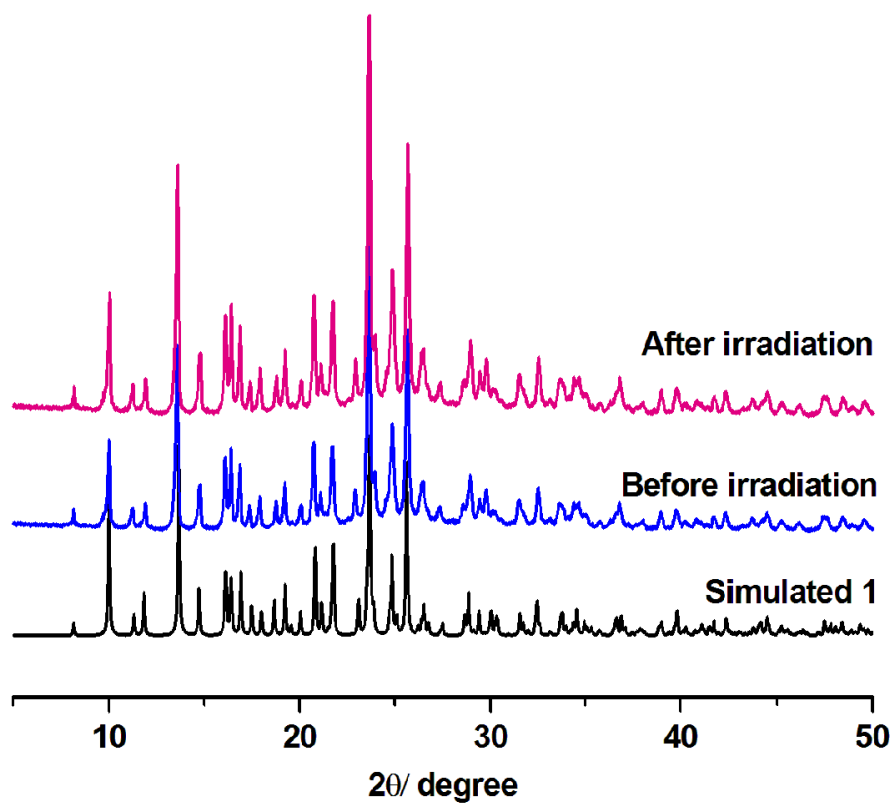

Figure S6. PXRD patterns of complex 1. 


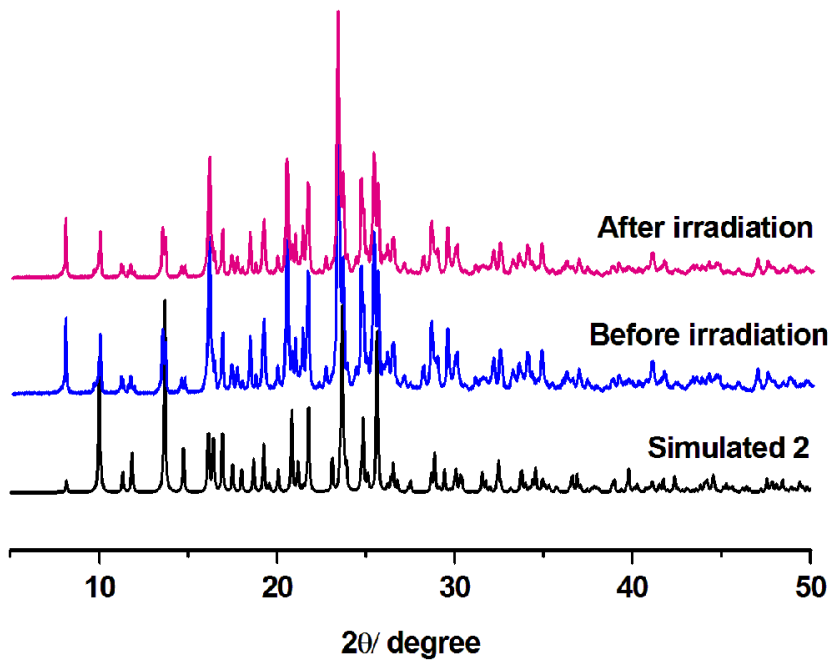

Figure S7. PXRD patterns of complex 2.

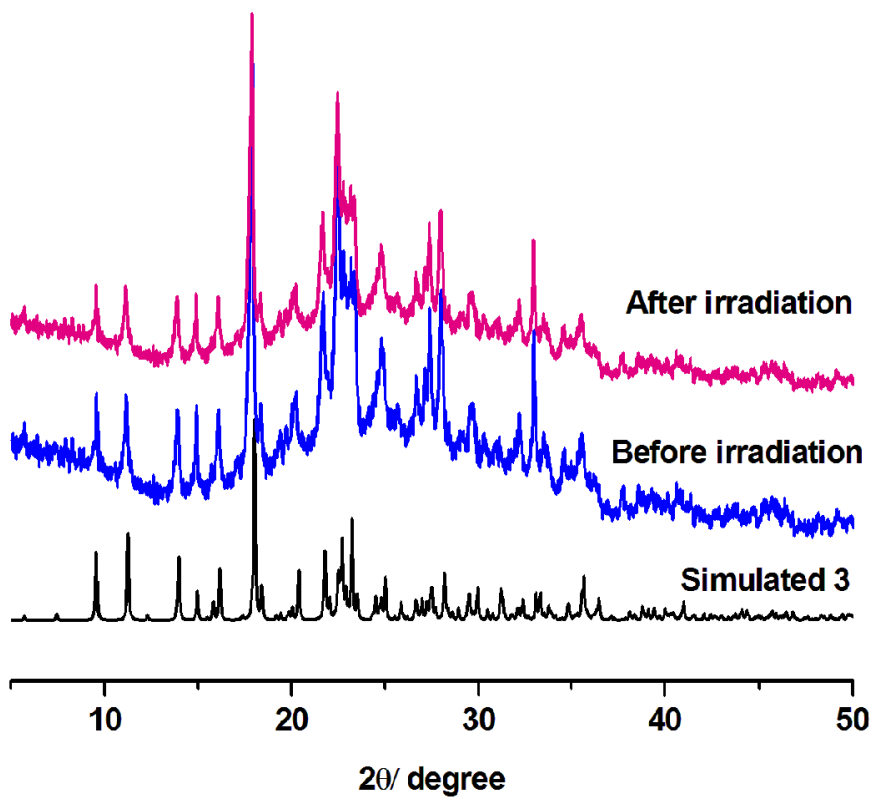

Figure S8. PXRD patterns of complex 3. 


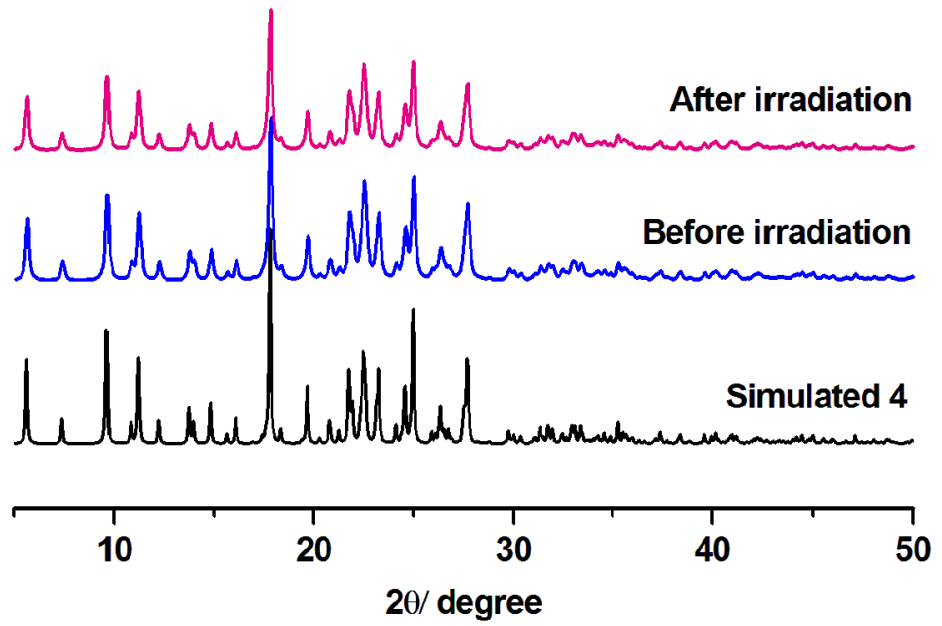

Figure S9. PXRD patterns of complex 4 .

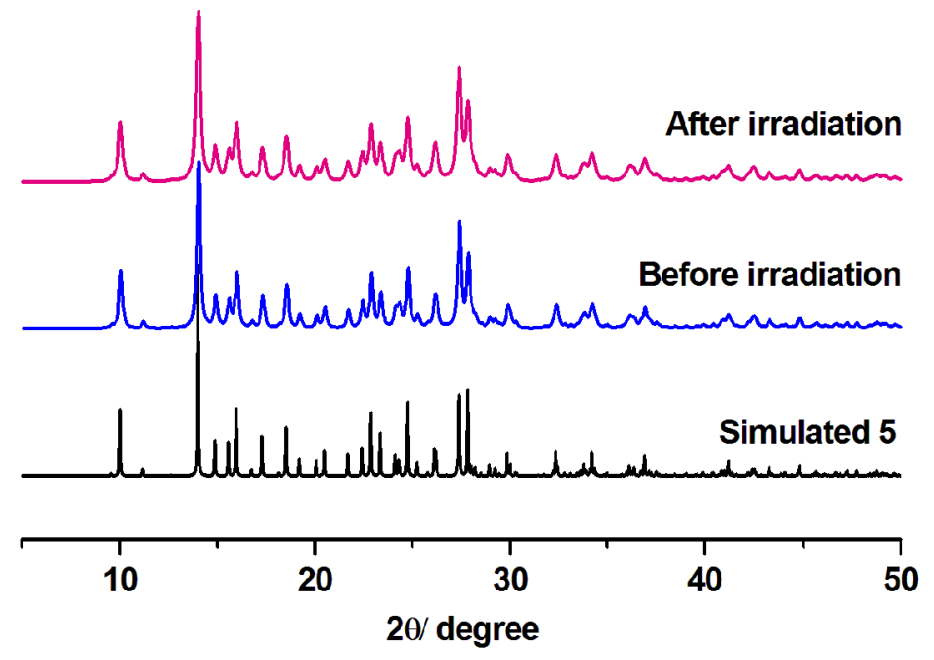

Figure S10. PXRD patterns of complex $\mathbf{5}$. 


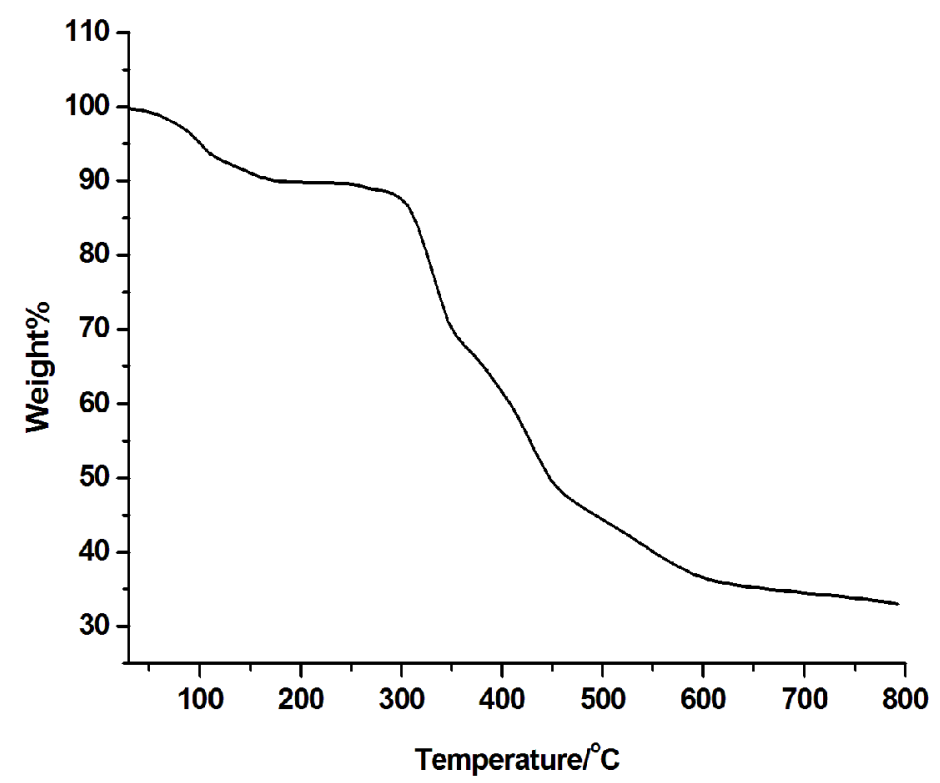

Figure S11. TGA curve of complex 1 in $\mathrm{N}_{2}$ with a ramp rate of $10 \mathrm{~K} / \mathrm{min}$.

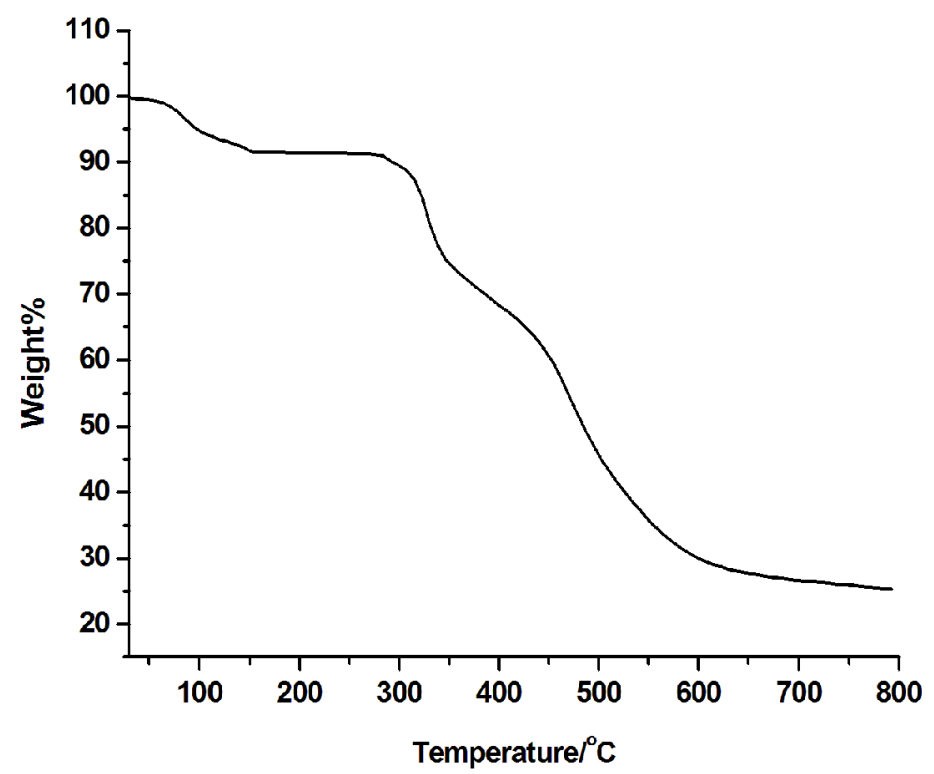

Figure S12. TGA curve of complex 2 in $\mathrm{N}_{2}$ with a ramp rate of $10 \mathrm{~K} / \mathrm{min}$. 


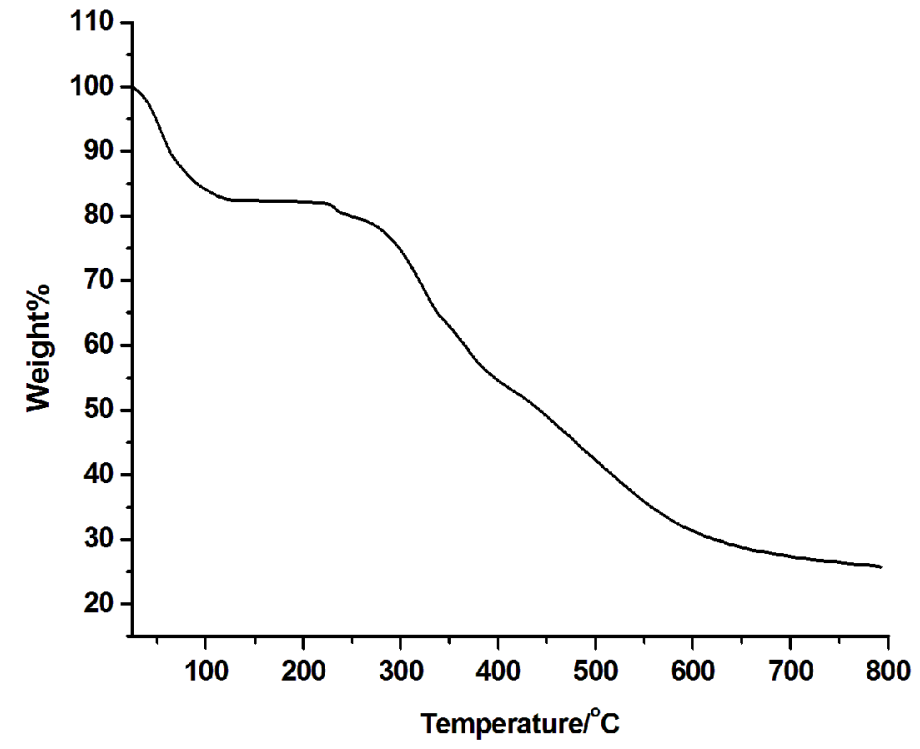

Figure S13. TGA curve of complex 3 in $\mathrm{N}_{2}$ with a ramp rate of $10 \mathrm{~K} / \mathrm{min}$.

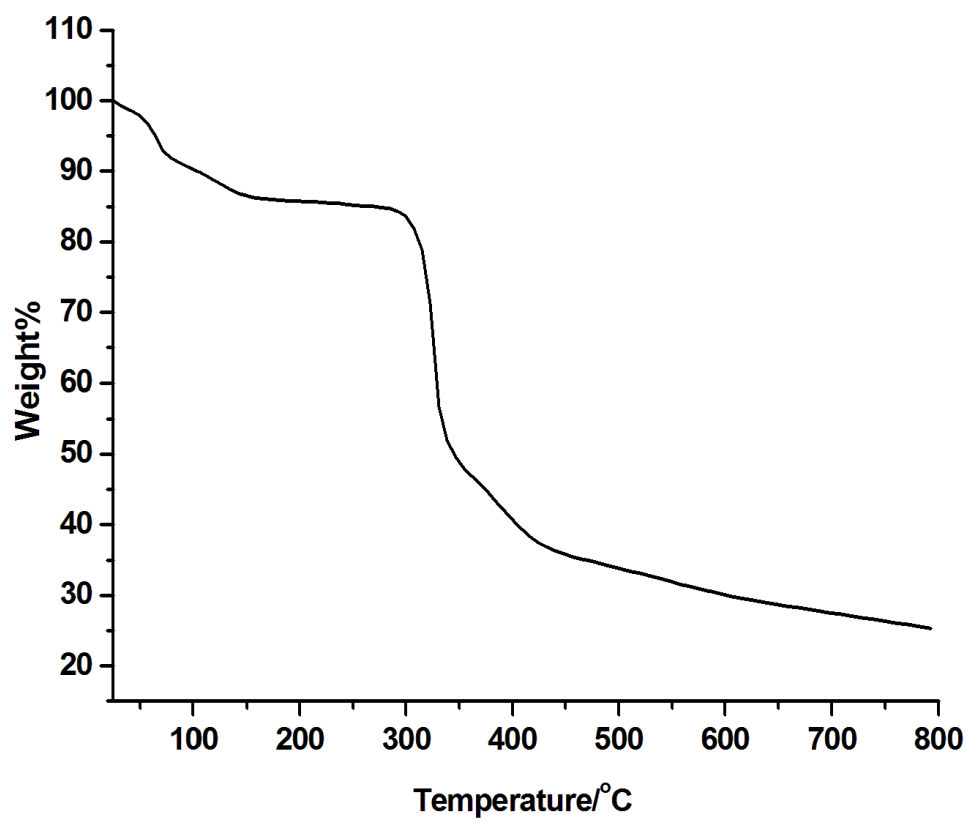

Figure S14. TGA curve of complex 4 in $\mathrm{N}_{2}$ with a ramp rate of $10 \mathrm{~K} / \mathrm{min}$. 


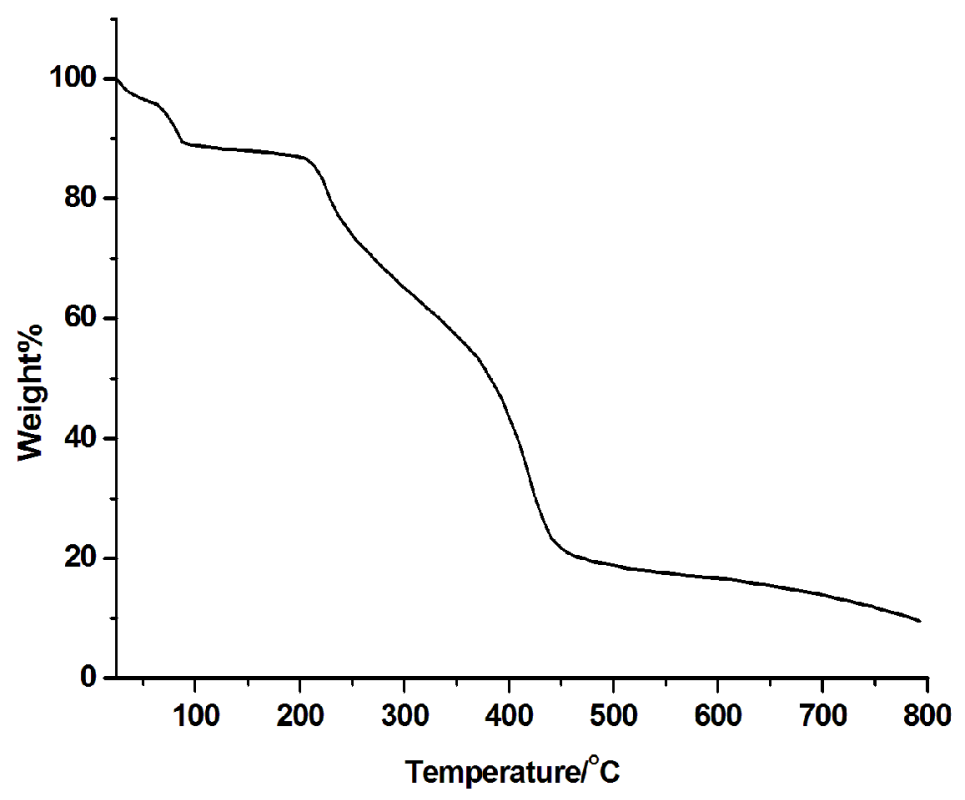

Figure S15. TGA curve of complex 5 in $\mathrm{N}_{2}$ with a ramp rate of $10 \mathrm{~K} / \mathrm{min}$.
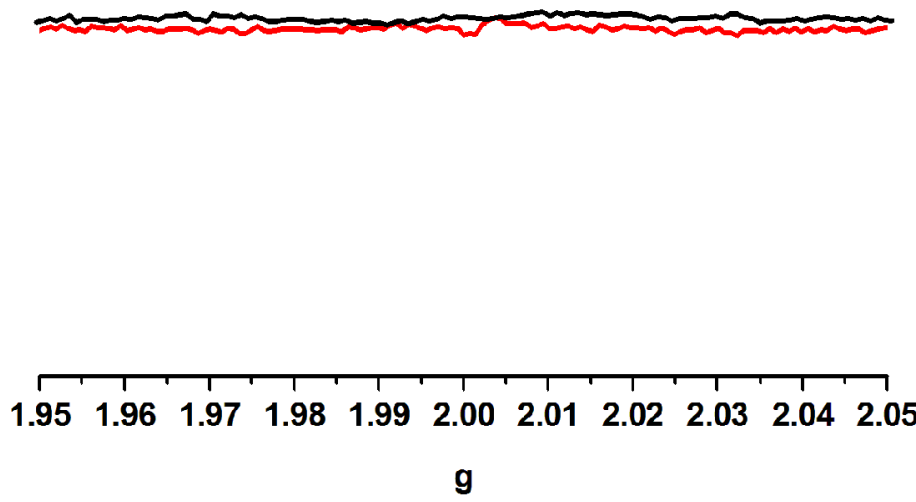

Figure S16. ESR spectra of complex 3 before and after irradiation. 


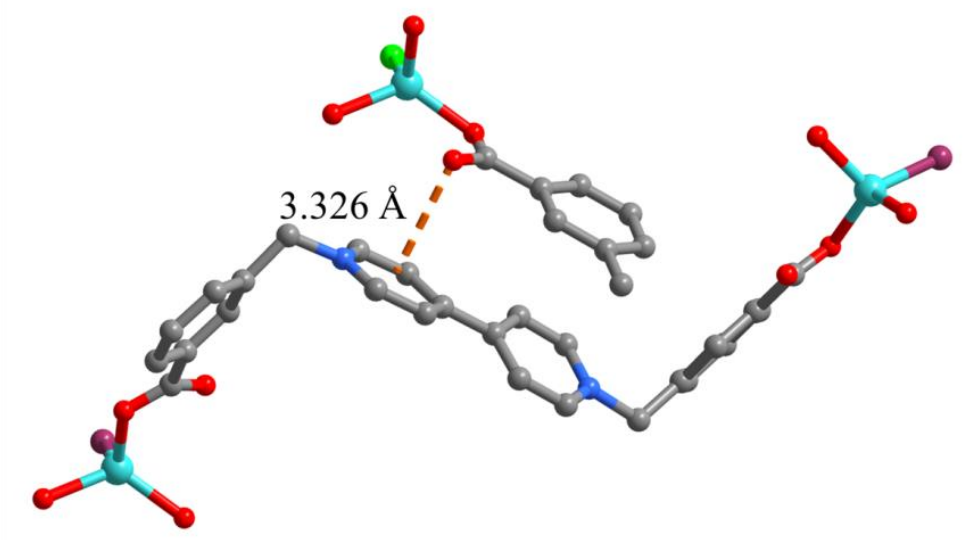

Figure S17. Distance between carboxylate $\mathrm{O}$ atom of bcbpy ligand and adjacent bipyridinium in complex 2 .

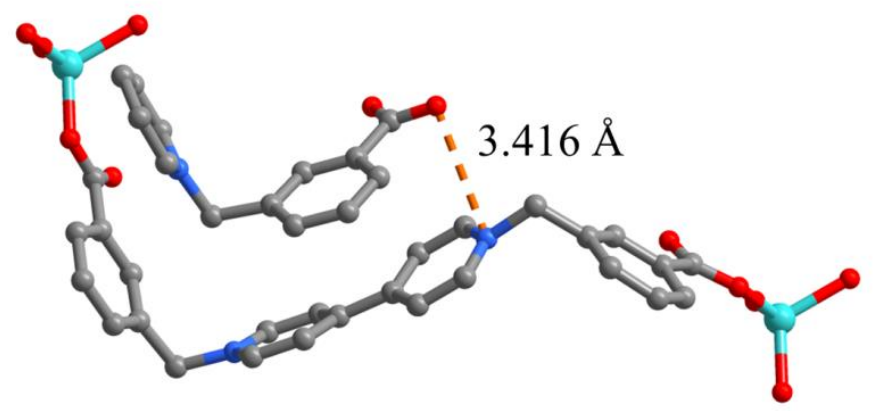

Figure S18. Distance between carboxylate $\mathrm{O}$ atom of bcbpy ligand and adjacent bipyridinium in complex 4 . 


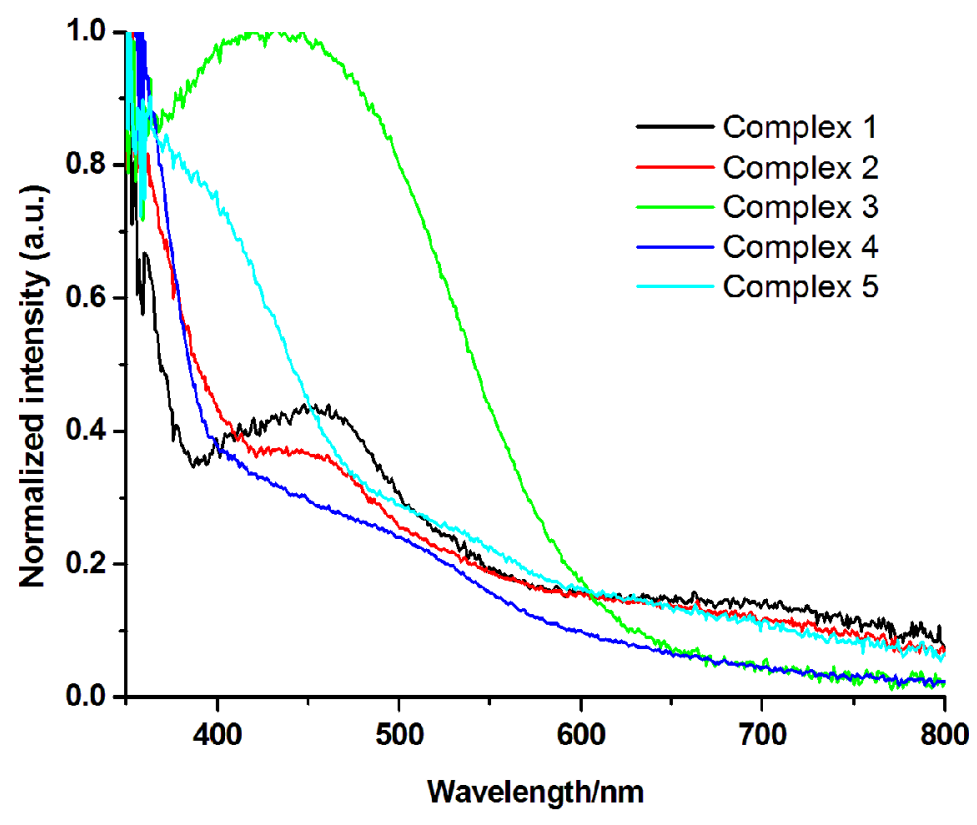

Figure S19. UV-vis spectra of complexes of complexes 1-5.

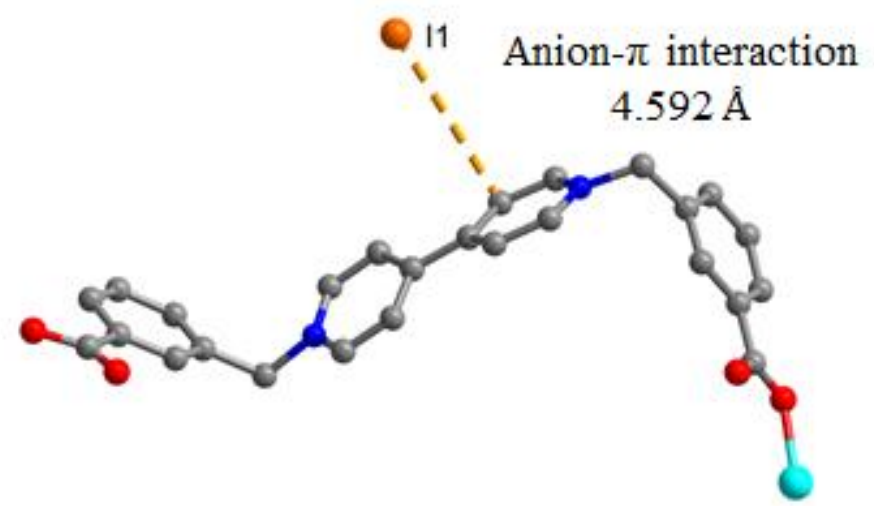

Figure S20. Distance between iodine ion and adjacent bipyridinium in complex 3 . 
(a)

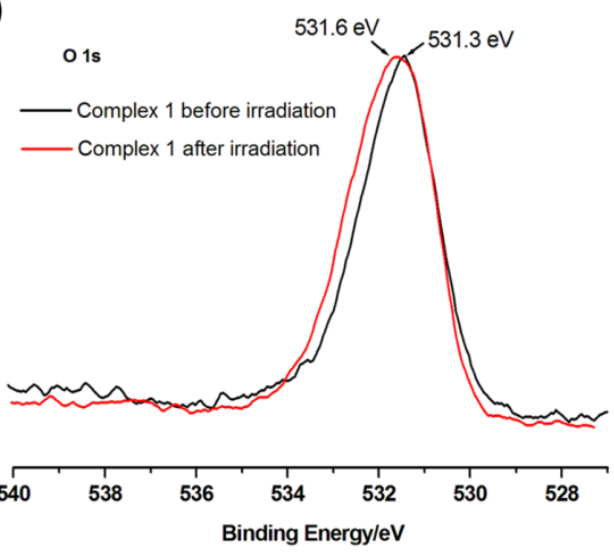

(b)

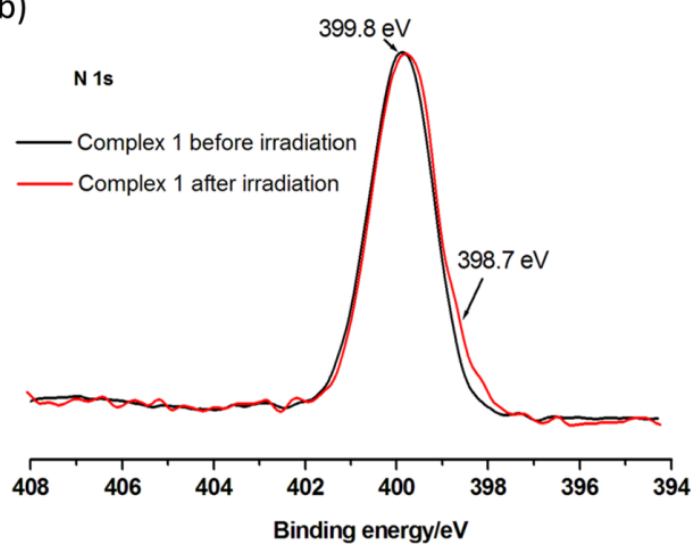

Figure S21. (a) O 1s XPS for complex 1 before and after irradiation. (b) N 1s XPS for complex 1 before and after irradiation.

(a)

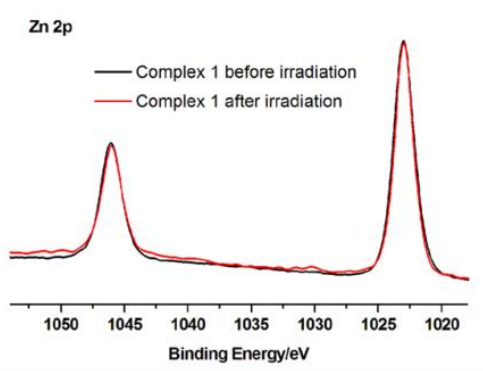

(b)

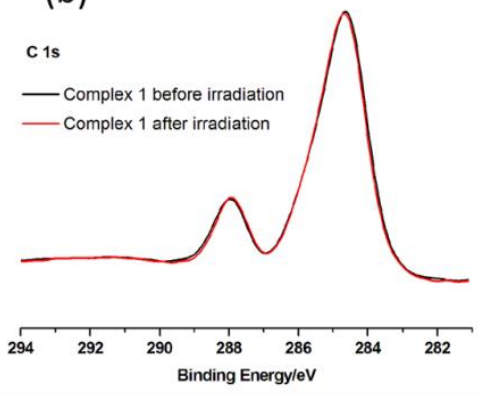

(c)

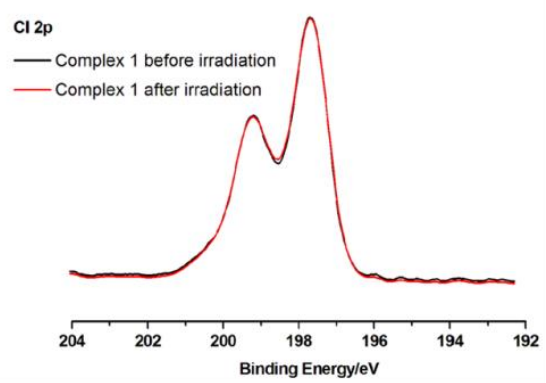

Figure S22. (a) Zn 2p XPS for complex 1 before and after irradiation. (b) C 1s XPS for complex 1 before and after irradiation. (C) $\mathrm{Cl} 2 \mathrm{p}$ XPS for complex 1 before and after irradiation. 


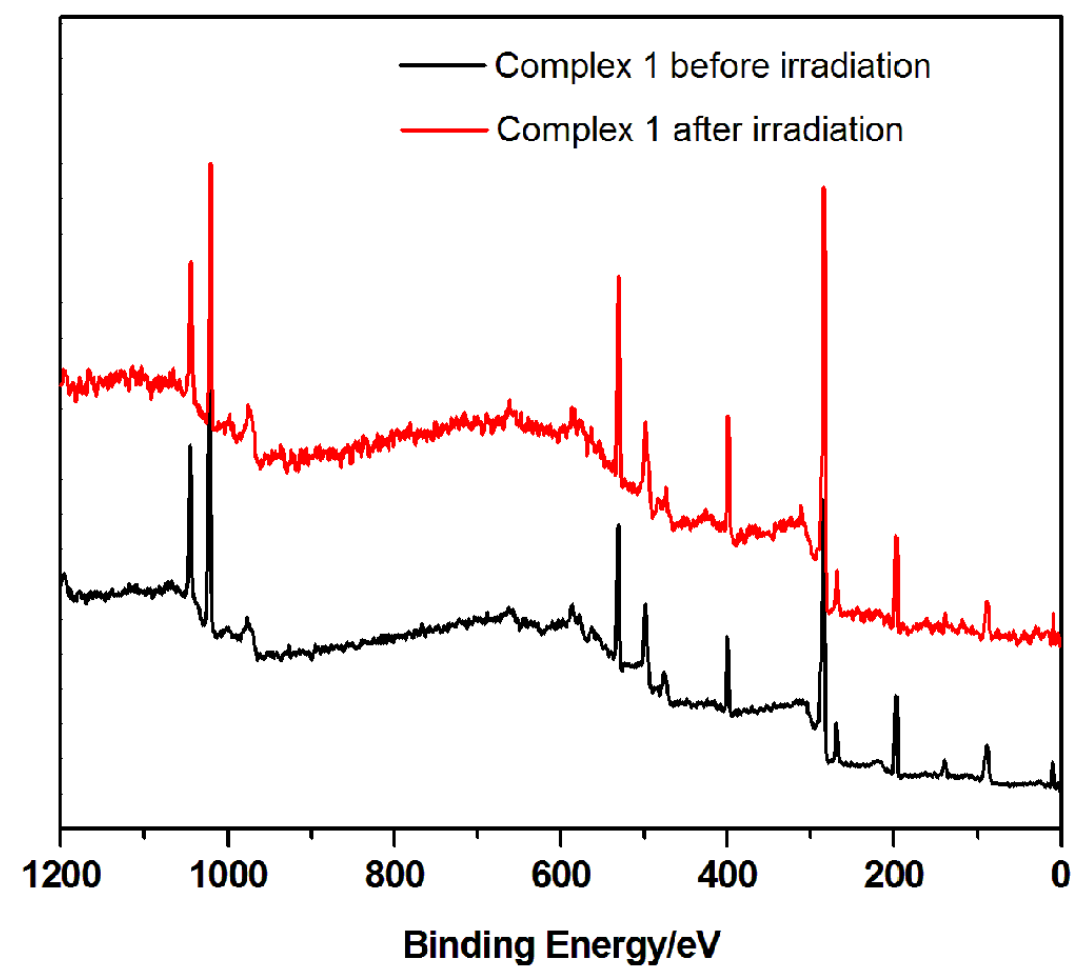

Figure S23. XPS for complex 1 before and after irradiation. 